\title{
0 compatibilismo teleológico de Leibniz: da ação livre ao livre arbítrio
}

\author{
Leibniz's teleological compatibilism: from free action to free will
}

do $10.21680 / 1983-2109.2021 v 28 n 57$ ID24575

\author{
Francisco das Chagas de Oliveira Freire \\ Universidade de Coimbra, Portugal \\ 0000-0002-8000-5447 \\ freirefranz@gmail.com
}

Resumo: Este artigo pretende reconstruir as principais decisões teóricas que caracterizam o conceito leibniziano de liberdade. Adota-se como método o confronto dialógico entre as concepções mais influentes em torno da problemática conciliação entre o paradigma mecanicista e matematizado do universo e a liberdade. Sob a influência do modelo mecanicista, influentes filósofos modernos reduziram o problema do livre arbítrio ao problema da livre ação. Hobbes, Locke e Hume identificaram a liberdade com a espontaneidade e a autonomia, consolidando um compatibilismo mecânico. Leibniz recepciona as noções de autonomia e espontaneidade. No entanto, a liberdade leibniziana, ao implicar também a inteligência e a contingência, introduz uma inversão na colocação do problema da liberdade. Ao invés de tentar alojar as estruturas fundamentais do querer nos interstícios do determinismo, Leibniz se questiona sobre como alojar o mecanicismo nas estruturas do querer teleológico de Deus. $\mathrm{O}$ artigo sublinha a centralidade da reassunção da noção de livre arbítrio e sua conciliação com a rejeição da libertas indifferentiae.

Palavras-chave: Liberdade; Determinismo; Compatibilismo; Inteligência; Contingência; Teleologia

\begin{abstract}
This article aims to reconstruct the main theoretical decisions that characterize the leibnizian concept of freedom. The method adopted is a dialogical confrontation between the most influential conceptions on the problematic reconciliation between the mechanistic and mathematical paradigm of the universe and freedom. Under the influence of the mechanistic model, influential modern philosophers reduced the problem of free will to the problem of free action. Hobbes, Locke and Hume identified freedom with spontaneity and autonomy, consolidating a mechanical compatibilism. Leibniz receives the notions of autonomy and spontaneity. However, Leibnizian freedom, by implying also intelligence and contingency, introduces an inversion in the posing of the problem of freedom. Instead of trying to lodge the fundamental structures of will in the interstices of determinism, Leibniz asks himself about how to lodge mechanicism in the structures of God's teleological will. The paper underlines the centrality of the reassumption of the notion of free will and its reconciliation with the rejection of libertas indifferentiae.
\end{abstract}

Keywords: Freedom; Determinism; Compatibilism; Intelligence; Contingency; Teleology. 
O princípio das possibilidades alternativas [uma pessoa é moralmente responsável pelo que fez somente se pudesse ter feito de outro modo] significa que a liberdade implica, além da ausência de impedimentos - contenção física, coerção, falta de habilidade, falta de oportunidade, compulsão - , a efetiva possibilidade de escolha (FRANKFURT, 1969, p. 829). Esse enunciado foi o pressuposto padrão do pensamento grego e medieval, considerado verdade incontestável, tem ampla aceitabilidade no quotidiano e na esfera jurídica. Apesar da aparente hegemonia, o princípio das possibilidades alternativas situa-se no âmago de uma grave controvérsia: a compatibilidade ou incompatibilidade entre liberdade e determinismo. O significado desse enunciado representa o núcleo hermenêutico do problema da imputabilidade: "O 'problema' da liberdade da vontade no sentido de imputabilidade é, desde sempre, a indagação a respeito do correto entendimento da seguinte sentença: a pessoa poderia ter agido de outra forma" (TUGENDHAT, 1987, p. 374). Esse enunciado é polissêmico e refere-se a uma questão central e irrenunciável: a efetividade e significado da liberdade. Todos os pensadores se depararam com a necessidade de lhe atribuir, de modo explícito e sistemático ou tácita e indiretamente, um significado.

Desde a consolidação da visão mecanicista e matematizada do universo, tornou-se necessária a reconstrução do conceito de liberdade. Os filósofos que a defenderam, tiveram de reconciliá-la com a descrição científica do mundo. O mecanicismo da física newtoniana, ao representar matematicamente o cosmos e prever estados futuros ou retrodizer estados passados, corroborou a tese de que o universo é determinado por uma complexa cadeia de relações causais estritamente necessárias. A geometrização do universo não foi assumida apenas como um aporte metodológico, ela assume a posição de fundamento metafísico, que descarta todo princípio teleológico. O mecanicismo vê confirmada a antiga suspeita determinista, intimamente vinculada à noção de destino ou fatalidade, de que as ações humanas estariam, assim como todo o mundo físico, sujeitas à necessidade causal. Todos os pensamentos, sentimentos e mecanismos psicológicos seriam invariavelmente pré-determinados e absolutamente previsíveis segundo nexos causais estritos e compulsórios. Consequentemente, o sentimento de decisão e influência sobre as próprias ações não seria mais que uma ilusão cognitiva. Num mundo plenamente determinado, causalidade determinada e vontade se identificam. Nesse caso, o indeterminismo não apenas contraria os fatos, mas alijaria a vontade da teoria da ação. No âmbito do determinismo mecânico, o enunciado "uma pessoa é moralmente responsável pelo que fez somente se pudesse ter feito de outro modo" impossibilita a imputabilidade moral, pois tudo o que acontece 
ocorre por necessidade ou seria preciso admitir o acaso. A liberdade não encontraria lugar nem no determinismo, nem no indeterminismo (WROBLEWSKI, 2014, p. 10).

Os filósofos que defenderam a liberdade diante do paradigma científico do universo são geralmente categorizados em função do modo como a relacionaram com o determinismo. Os incompatibilistas defendem que se nossas ações são determinadas por causas naturais, então o agir livre e a responsabilidade moral são ilusões. A liberdade e o determinismo são incompatíveis. Os compatibilistas, por sua vez, sustentam que nossas ações podem ser determinadas por causas naturais e ainda ser livres no sentido necessário para o agir moral e para a responsabilidade. A liberdade e o determinismo são compatíveis (WOOD, 1998, p. 239). Sob a influência do modelo mecanicista, influentes filósofos modernos reduziram o problema do livre arbítrio ao problema da livre ação, fundando a tendência consolidada, também entre os autores contemporâneos, de tratar a expressão "problema do livre arbítrio" como título meramente honorífico para o problema da livre ação (KANE, 2014, p. 37).

O presente artigo pretende reconstruir as principais decisões teóricas que caracterizam o conceito leibniziano de liberdade, em seus méritos e limites em relação à noção de imputabilidade moral. Adotaremos como método o confronto dialógico entre as concepções mais influentes em torno da problemática conciliação entre o paradigma mecanicista e matematizado do universo e a liberdade. Partiremos do célebre e influente embate entre Hobbes e Bramhall, que definiu, em grande parte, os termos do debate. Espinosa, Locke e Hume serão trazidos à discussão, de modo que compreendamos o problema que Leibniz visava a solucionar, assim como o instrumental conceitual à disposição para a tessitura de uma solução. Coube a Leibniz a ousada tentativa de reposicionar, de modo autêntico e profundo, o problema da liberdade no âmbito da vontade. Defende-se que a reflexão leibniziana representa a reassunção do princípio de possibilidades alternativas dentro dos marcos estabelecidos pelo paradigma compatibilista. Isto é, Leibniz pretende conciliar a rejeição da libertas indifferentiae com a afirmação de que o arbítrio é livre. Leibniz reintroduz a teleologia no âmbito da discussão sobre a liberdade, realizando uma inversão na colocação do problema da liberdade. Os compatibilistas modernos se perguntaram sobre como alojar as estruturas fundamentais do querer nos interstícios do determinismo mecanicista; Leibniz se pergunta sobre como alojar o mecanicismo nas estruturas do querer teleológico de Deus. 


\section{COMPATIBILISMO MECÂNICO}

Em 1645, a peleja sobre a livre vontade conhece no debate entre Bramhall (1594-1663) e Hobbes (1588-1679) uma reedição da disputa histórica - que estabeleceu os termos do debate entre os filósofos modernos e influenciou o desenvolvimento da problemática em Leibniz - sob a égide do mecanicismo originado na revolução científica. De um lado, John Bramhall, bispo anglicano e representante da escolástica cristã, entende que a ação humana é exercida através da vontade, entendida como faculdade eletiva. Bramhall opõe ao necessitarismo mecanicista de Hobbes uma postura libertária. Para Bramhall, qualquer iniciativa que vise compatibilizar liberdade e necessidade revelar-se-á infrutífera, pois a necessidade consiste em uma determinação antecedente, ao passo que "a verdadeira liberdade consiste no poder eletivo da vontade racional". O fulcro do argumento é que "aquilo que é necessitado pode concordar suficientemente bem com minha fantasia ou desejo, e obter meu subsequente consentimento; mas aquilo que é determinado sem minha concordância ou consentimento não pode ser objeto de minha eleição" (BRAMHALL, 1999, p. 43). Para Bramhall, a vontade seria a faculdade legislativa da mente humana, dotada de duas funções: a função eletiva (imperatus) e a função executiva (actus elicitus). No exercício da função eletiva, a vontade escolhe uma das possíveis alternativas de ação. Essa afirmação comporta dois pressupostos: por um lado, a compulsão deriva da vontade, que, por sua vez, não é compelida por nada. A eleição entre possibilidades implica a efetiva existência de alternativas na eleição. Essa descrição coincide com a admissão da libertas indifferentiae, entendida como ausência de toda necessitação causal da vontade (BRAMHALL, 1999, p. 9). Uma vez que a liberdade implica a possibilidade de eleição, isto é, a possibilidade de agir de outra forma, liberdade e necessidade são conceitos logicamente incompatíveis.

Do lado oposto no debate, Hobbes, que influenciado por Galileu Galilei (1564-1642) e Andreas Vesalius (1514-1564), adota a visão mecanicista do mundo, segundo a qual a natureza e as ações humanas são governadas somente pelas leis do movimento. Hobbes entendia que "Tudo o que é produzido é produzido necessariamente, pois tudo o que é produzido tem uma causa suficiente que o produziu; e, portanto, também as ações voluntárias são necessitadas". A liberdade, tanto nas criaturas irracionais e inanimadas quanto nas criaturas racionais, é "simplesmente a ausência de todo impedimento à ação que não está contido na natureza ou qualidade intrínseca do agente" (HOBBES, 1999, p. 38). No capítulo XXI do Leviatã, que trata da liberdade dos súditos, Hobbes atribui a liberdade ao homem e nega que seja propriedade de uma faculdade: "do uso da expressão livre-arbítrio não é possível inferir nenhuma liberdade da vontade, do desejo ou da inclinação, mas apenas a liberdade do homem" (HOBBES, 2003, p. 180). Para Hobbes, carece de sentido afirmar que uma ação querida não é livre. Basta que uma ação comece na vontade para que ela seja considerada livre (HOBBES, 1991, p. 16). As paixões 
não procedem da vontade, elas são a vontade. O conceito hobbesiano de liberdade coincide com a noção de espontaneidade e autonomia. O decreto de Deus é a soma de todas as coisas, agora existentes, que concorre como causa para a ocorrência do que se segue e determina o mundo a ser tal como é (HOBBES, 1999, p. 20). Para Hobbes, a compatibilidade entre liberdade e necessidade assegura os conceitos de imputabilidade moral, providência e onipotência divina. Todas as ações que derivam da vontade são livres e inseridas numa cadeia causal necessária, nos termos da mecânica, da qual Deus é a causa primeira.

A liberdade e a necessidade são compatíveis, o que ocorre com a água que não tem apenas a liberdade, mas também a necessidade de descer pelo canal, também ocorre com as ações que os homens voluntariamente praticam: estas, como derivam de sua vontade, derivam da liberdade, e contudo, porque todo ato da vontade dos homens, todo desejo e inclinação deriva de alguma causa, e esta de uma outra causa, numa cadeia contínua (cujo primeiro elo está na mão de Deus, a primeira de todas as causas), eles derivam também da necessidade. De modo tal que para quem pudesse ver a conexão dessas causas a necessidade de todas as ações voluntárias dos homens pareceria manifesta. Portanto Deus, que vê e dispõe todas as coisas, vê também que a liberdade que o homem tem de fazer o que quer é acompanhada pela necessidade de fazer aquilo que Deus quer, e nem mais nem menos do que isso. Porque embora os homens possam fazer muitas coisas que Deus não ordenou, e das quais, portanto, não é autor, não lhes é possível ter paixão ou apetite por nada de cujo apetite a vontade de Deus não seja a causa. E se acaso a sua vontade não garantisse a necessidade da vontade do homem, e consequentemente de tudo o que depende da vontade, a liberdade dos homens seria uma contradição e um impedimento à onipotência e liberdade de Deus. E isto é suficiente (quanto ao assunto em pauta) sobre aquela liberdade natural que é a única propriamente chamada liberdade. (HOBBES, 2003, p. 181)

A controvérsia repercute e se aprofunda entre os filósofos modernos que, sob o influxo da paradigmática imagem mecanicista do mundo, rejeitaram a noção de libertas indifferentiae como incompatível com as noções de causalidade e necessidade vigentes. No Ensaio acerca do Entendimento Humano, John Locke define a liberdade como "poder em certo agente para fazer ou deixar de fazer qualquer ação particular, segundo a determinação ou pensamento da mente, por meio do qual uma coisa é preferida a outra" (LOCKE, 1690, II, XXI, 8) ${ }^{1}$. Para Locke, a liberdade se refere exclusivamente à ação, "voluntário, então, não é oposto a necessário, mas a involuntário" (LOCKE, 1690, II, XXI, 14). Seguindo Hobbes, Locke concebe a ideia de liberdade como pertencendo ao sujeito agente, ou seja, àquele que tem o poder de agir ou deixar de agir, e jamais à volição. O famoso problema da liberdade da vontade, considerado capital para a imputabilidade humana por

\footnotetext{
${ }^{1}$ LOCKE, John. An Essay Concerning Human Understanding. Londres: Printed by Eliz. Holt, 1690. Ao invés de indicar a página, indicarei na sequência o livro, o capítulo e o número do parágrafo. Farei uso da versão integral em inglês e farei as traduções somente quando não puder tomá-las da tradução de Anoar Aiex, feita a partir da edição abreviada do Ensaio editada por A. D. Woozley. Woozley usou a $5^{\text {a }}$ edição da obra. Ensaio acerca do Entendimento Humano. Tradução de Anoar Aiex. Editora Nova Cultural, São Paulo, 1999.
} 
grande parte da tradição filosófica, é considerado inapropriado, ininteligível, irracional e absurdo: "a liberdade refere-se tão pouco à vontade como a rapidez do movimento ao sono, ou a quadratura à virtude" (LOCKE, 1690, II, XXI, 14).

Para Locke, "O que determina a vontade a qualquer mudança de operação é alguma inquietação atual, que é - ou pelo menos sempre acompanha - o desejo" (LOCKE, 2007, II, XXI, 71). Locke mitiga o determinismo da vontade ao estabelecer uma distinção entre a necessidade interior e a necessidade física. A satisfação de qualquer desejo particular pode ser suspensa da determinação da vontade até que examinemos de forma madura se o bem aparente em questão realmente faz parte da nossa verdadeira felicidade. Embora a vontade seja necessariamente influenciada pelas inquietações atuais, o conteúdo da inquietação é algo empírico e indeterminado, pois varia segundo as circunstâncias e as mais variadas sensibilidades individuais. A inquietação atual não pode ser pensada em termos universais como se fosse uma estrutura a priori, pois a moral lockeana não comporta qualquer princípio moral a priori. A vontade lockeana não se orienta, portanto, a um bem metafisicamente considerado ou algo universalizável. Alguns princípios especulativos, ainda que não sejam inatos, são pelo menos autoevidentes, sem necessidade de provas. No entanto, podemos certamente questionar a razão de qualquer princípio prático. Os princípios morais ou as máximas exigem menos concordância do que os especulativos (SCHNEEWIND, 1994, p. 200).

Hume manteve a discussão sobre a noção de liberdade no âmbito da ação. $\mathrm{Na}$ verdade, a reflexão desenvolvida por Hume sofreu uma sensível evolução quando se analisa comparativamente os textos referentes à liberdade no Tratado da Natureza Humana e no Investigação sobre o entendimento humano e sobre os princípios da moral. Hume transita de uma doutrina da necessidade - como negação da liberdade - para um compatibilismo, ainda que meramente conceitual e psicológico (BOTTERILL, 2002, p. 304). Hume associa causalidade, necessidade e imputabilidade moral. A liberdade definida por oposição à necessidade é acaso. Sabe-se que nada existe sem uma causa e que acaso é um conceito meramente negativo, pois não designa nada de real na natureza. A liberdade, enquanto oposta à necessidade, não é coerção, é o mesmo que o acaso, o qual universalmente se reconhece não possuir existência. A ação livre e responsável é aquela que encontra em seu agente sua causa (HUME, 2007, p. 85). Hobbes, Locke e Hume veem na necessidade uma condição sine qua non para a responsabilidade moral. Liberdade e necessidade são expressões da mesma cadeia causal a qual estão submetidas todas as coisas. A teoria da ação é, portanto, inserida na semântica da necessidade natural como um elemento mais na cadeia da necessidade. O homem vulgar, que 
toma as coisas por sua aparência "atribui a incerteza dos eventos a tal incerteza nas causas"; o filósofo, no entanto, sabe que até "a contrariedade dos eventos não pode proceder de qualquer contingência na causa, mas da operação secreta de causas contrárias" (HUME, 2007, p.78).

O único objeto adequado de ódio ou vingança é uma pessoa ou criatura dotada de pensamento e consciência; e quando algumas ações criminosas ou prejudiciais excitam essa paixão, isso só ocorre pela relação, ou conexão, que essas ações mantêm com a pessoa. Por sua própria natureza, ações são temporárias e perecíveis, e quando não procedem de alguma causa no caráter e disposição da pessoa que as realizou, elas não podem nem redundar em sua honra se forem boas ações, nem em sua infâmia, se forem más. Nesse caso, as ações, elas mesmas, podem ser repreensíveis, podem ser contrárias a todas as regras de moralidade e da religião, mas a pessoa não será responsável por elas, e, dado que não procedem de nada que seja durável e constante no agente, e não deixam para trás de si nada que tenha essas características, é impossível que essa pessoa deva tornar-se, por causa delas, objeto de punição ou vingança. Assim, de acordo com o princípio que nega a necessidade e, consequentemente, as causas, um homem, após ter cometido o crime mais horrendo, está tão puro e sem mácula como no instante de seu nascimento, e seu caráter não está de nenhum modo envolvido em ações, dado que não é dele que derivam, e a perversidade destas últimas não pode jamais ser apresentada como uma prova de corrupção do primeiro. (HUME, 2007, p.87)

Hobbes, Locke e Hume rejeitam a libertas indifferentiae, considerando-a como um acaso, isto é, negação da causalidade e da legalidade que caracteriza todos os eventos da natureza. Hume (2001, p. 440) adverte sobre a confusão entre espontaneidade e liberdade de indiferença. A espontaneidade opõe-se à violência, a liberdade de indiferença significa uma negação da necessidade e das causas. Esses autores cosmologizam a noção de liberdade, entendendo-a como espontaneidade e autonomia. As noções de espontaneidade e autonomia não comportam a necessidade de alternativa. A escolha espontânea pode estar condicionada por profundos, complexos e inconscientes determinantes biológicos, psicológicos e histórico-sociais. Ademais, a ausência de condicionamentos intrínsecos ou introjetados não exclui a possibilidade de escolhermos a única alternativa efetivamente possível. A liberdade não é uma ideia que pertence à vontade ou preferência e não implica a necessidade de alternativas. Locke exemplifica considerando a hipótese de uma pessoa que é levada para uma sala enquanto dorme e trancada com alguém que ansiava ver. Ao acordar, feliz pela agradável companhia, essa pessoa escolhe permanecer na sala, embora desconheça a falta de opção. Locke insiste que ninguém duvidaria do caráter livre dessa escolha, o que comprovaria que a liberdade não se refira à vontade ou preferência (LOCKE II, XXI, 10). Se propuséssemos a eles que atribuíssem um sentido à assertiva "uma pessoa é moralmente responsável pelo que fez somente se pudesse ter feito de outro modo", eles responderiam 
que o enunciado carece completamente de sentido se estivermos nos referindo a querer de outro modo. Não há alternativa anterior à volição. Querer é querer algo. Enquanto algo não é querido, não há volição. Há uma efetiva coincidência entre a faculdade de querer e a representação de algo querido. Então, uma pessoa agiria de modo diverso somente se fossem outras as condições causais envolvidas na ação. A pessoa é responsável, não por não ter feito de outro modo, mas porque há um vínculo causal necessário entre a ação realizada e o caráter de sua vontade.

\title{
2 COMPATIBILISMO TELEOLÓGICO
}

Leibniz representa uma inovação na abordagem da relação entre liberdade e necessidade. Leibniz pretende conciliar a rejeição da libertas indifferentiae com a afirmação de que o arbítrio é livre. Para tanto, atribui à liberdade três características fundamentais: inteligência, espontaneidade e contingência.

\begin{abstract}
A liberdade [...] consiste na inteligência, que envolve um conhecimento distinto do objeto da deliberação; na espontaneidade, a partir da qual nós nos determinamos; e na contingência, isto é, na exclusão da necessidade lógica ou metafísica. A inteligência é como que a alma da liberdade, e o resto é como que o seu corpo e a sua base. A substância livre se determina por ela mesma, e isso seguindo a motivação do bem apercebida pelo entendimento que a inclina sem a obrigar. (LEIBNIZ, 2017, p. 338).
\end{abstract}

Apesar da definição sucinta e clara, Leibniz reconhece que "o termo liberdade é muito ambíguo". Ele distingue liberdade de direito e liberdade de fato, liberdade de ação e liberdade de arbítrio. A liberdade de direito distingue juridicamente o livre do escravo. A liberdade de fato, por sua vez, consiste no poder fazer o que se quer ou o poder querer como se deve. A liberdade de querer pode ser compreendida de duas formas: ou na liberdade de espírito ao modo estoico - ou seja, visto que tudo é necessário, trata-se de não se deixar possuir pelas paixões - ou no livre arbítrio, entendido como o "querermos que as razões ou impressões mais fortes que o entendimento apresenta à vontade não impeçam o ato da vontade de ser contingente, e não lhe deem uma necessidade absoluta e, por assim dizer, metafísica" (LEIBNIZ, 1980, p. 122).

\subsection{A CONCILIAÇÃO DA LIBERDADE DIVINA COM A LIBERDADE HUMANA}

A liberdade humana só encontra plena inteligibilidade à luz da liberdade criadora. Eis o modo como Leibniz aborda o desafio de conciliar a liberdade e a necessidade: "desde muito tempo, uma questão lança o gênero humano na perplexidade: como a liberdade e a contingência podem se conciliar com a série das causas 
e a providência" (LEIBNIZ, 1990, p. 97). Leibniz retoma o problema apresentado por Hobbes no Leviatã e na controvérsia com Bramhall, registrada na Questions concerning liberty, necessity and chance (1645): a conciliação, antes de tudo, da liberdade divina com a liberdade humana. Como vimos acima, a liberdade da vontade no homem "seria uma contradição e um impedimento à onipotência e liberdade de Deus" (HOBBES, 2003, p. 181). Nota-se prontamente que Leibniz desloca a questão do âmbito ético e antropológico para o ontoteológico. Posta a nível teológico, a resposta para a questão afeta simultaneamente os conceitos de liberdade, verdade, inteligência e vontade divina e humana.

A perplexidade resulta da aparentemente insolúvel conciliação entre os conceitos de presciência e providência divinas com a noção de contingência e livrearbítrio. Se admitirmos a contingência, poder-se-ia dizer que Deus não seria capaz de conhecer de antemão a sequência de fatos decorrentes do ato criador, pois haveria sempre a possibilidade de alteração na cadeia de acontecimentos. Simultaneamente, a providência de Deus para o mundo seria ameaçada se os seus desígnios fossem permanentemente desbaratados por alguma ineficiência na determinação causal. Uma contingência que neutralizasse os conceitos de presciência e providência divinas anularia qualquer possibilidade de teleologia. Por outro lado, a liberdade humana, sob todos os aspectos, seria dissolvida se as noções de presciência e providência divinas excluíssem a contingência. De fato, a previsão infalível de uma escolha moral contingente é um mistério impossível de conceber, assim como é igualmente incompreensível que uma criatura sem liberdade peque (LEIBNIZ, 2017, p. 386). Eis o dilema teológico que Leibniz deve resolver e que impacta o conceito de liberdade humana. Poderíamos, então, sintetizar nossa breve pesquisa sobre o conceito leibniziano de liberdade pelas perguntas: visto que tradicionalmente a essência de Deus comporta onisciência, onipotência, eternidade e suma bondade, em que sentido Deus é livre? Poderia Deus criar um mundo que não fosse o melhor? Como tais respostas impactam sobre o conceito de liberdade humana?

Leibniz, criticando Espinosa, defende uma conciliação entre a necessidade e a liberdade na divindade. Da necessária existência de Deus não resulta que suas escolhas sejam necessárias.

Com relação ao que diz Espinosa (Ética, I, prop. 34), que Deus é, pela mesma necessidade, causa de si mesmo e causa de todas as coisas, e (Tratado Político, capítulo II, $\$ 2$ ) que o poder das coisas é o poder de Deus, não o admito. Deus existe necessariamente, mas ele produz livremente coisas. Deus produziu o poder das coisas, mas ele é distinto do poder divino. As coisas operam a si mesmas, mesmo que tenham recebido as forças para agir. (LEIBNIZ, 1854, p.37) 
De fato, Espinosa (1632-1677), sustenta um monismo no qual concebe um Deus despersonalizado e geométrico, identificado com a natureza (ESPINOSA, 2007, p. 21). Nesse contexto, Espinosa elabora um conceito de liberdade metafísica, segundo o qual é livre a coisa que existe exclusivamente pela necessidade de sua natureza e que por si só é determinada a agir. Ao passo que é necessária, ou melhor, coagida, aquela coisa que é determinada por outra a existir e a operar de maneira definida e determinada (ESPINOSA, 2007, p.13). Disso resulta que somente Deus é causa livre, pois só Ele existe exclusivamente pela necessidade de sua natureza, e, enquanto causa, é imanente. Mas tal liberdade de ser, que em certa medida se aproxima da noção de espontaneidade, em nada se confunde com a liberdade do arbítrio (ESPINOSA, 2007, p. 63). Dos pressupostos metafísicos e teológicos de Espinosa não podem resultar para o homem nada mais que uma liberdade ilusória, fruto da ignorância: "por estarem conscientes de suas volições e de seus apetites, os homens se creem livres, mas nem em sonho pensam nas causas que os dispõem a ter essa vontade e esses apetites, porque as ignoram" (ESPINOSA, 2007, p. 65).

Embora critique os pressupostos de Espinosa e Hobbes, Leibniz reconheceu no ensaio Sobre a liberdade, a contingência e a providência (1689) sua proximidade vertiginosa do necessitarismo.

De minha parte, havia observado que nada sucede por casualidade ou por acidente, exceto se consideramos algumas substâncias particulares, assim como a fortuna separada do destino é uma palavra vã e que nada existe a não ser que se cumpram os requisitos particulares - se bem que do conjunto dos mesmos se segue, por sua vez, o mesmo resultado - para que a coisa exista. Nisto me aproximava um pouco da opinião daqueles que consideram todas as coisas absolutamente necessárias e que julgam suficiente para que exista liberdade, que tudo esteja isento de coação, ainda que fique submetido à necessidade, e que não distinguem o conhecimento verdadeiro com certeza, o infalível, do necessário. (LEIBNIZ, 1990, p. 97)

Adams (1994, p. 10) sustenta que Leibniz defendeu várias concepções do problema da contingência e manteve simultaneamente mais de uma solução. Apoiando-se na carta de Leibniz a Wedderkopf, de maio de 1671, Adams afirma que a primeira solução principal foi o necessitarismo. O argumento principal para a necessidade de todos os eventos não é baseado na teoria analítica da verdade, mas na natureza de Deus e no princípio de razão suficiente (ADAMS, 1994, p. 12).

O destino é o decreto de Deus ou a necessidade dos acontecimentos. Coisas predestinadas são aquelas que necessariamente acontecerão [...] Se Deus decreta sobre todas as coisas, então ele é o autor de absolutamente tudo. Seja como for, há dificuldades. Pois se Deus decreta sobre todas as coisas e as coisas entram em conflito com seu decreto, Ele não será onipotente. Mas se Ele não decretar sobre todas as coisas, 
parece que Ele não é onisciente [...] Pois é necessário que todas as coisas sejam remetidas a alguma razão, e não podemos parar até chegarmos a uma razão primária, caso contrário é preciso admitir que algo pode existir sem uma razão suficiente para existir, o que destrói a demonstração da existência de Deus e muitos outros teoremas filosóficos. Qual, então, é a razão última da vontade divina? O intelecto divino. Pois Deus quer aquelas coisas que entende serem as melhores e mais harmoniosas e Ele as seleciona, por assim dizer, a partir do número infinito de todos os possíveis. (LEIBNIZ, 1989, p. 146)

A carta de Leibniz a Wedderkopf nos remete inevitavelmente para o problema da conciliação entre a liberdade divina - providência, onisciência e onipotência divinas - e a liberdade humana. Esse trecho evidencia, mais que um argumento cabal em prol do necessitarismo, a aporia imposta pelo paradigma mecanicista. Não se trata tanto de uma primeira solução, quanto de uma, entre tantas outras tentativas, de formulação adequada dos termos do problema. O filósofo pontua: "seja como for, há dificuldades". A carta de Leibniz a Wedderkopf representa um momento no processo de discernimento e amadurecimento de uma solução. Ao afirmar que Deus escolhe "a partir do número infinito de todos os possíveis", Leibniz já explicita o germe da solução que adotará e que analisaremos adiante. Importa aqui salientar que somente por um árduo processo - que não cabe abordar exaustivamente nesse artigo - Leibniz distingue necessitarismo e determinismo e compatibiliza determinismo, contingência e liberdade da vontade.

A conclusão da carta de Leibniz a Wedderkopf apresenta Deus como necessitado para o melhor possível. Isso ocorre porque o conceito de liberdade que adota na carta a Wedderkopf ainda não implica a contingência, apenas a inteligência e a espontaneidade.

Visto que Deus é a mente mais perfeita, é impossível para Ele não ser afetado pela mais perfeita harmonia, e, portanto, ser necessitado para o melhor possível pela própria idealidade das coisas [...] Daí segue-se que o que quer que tenha acontecido, está acontecendo ou acontecerá é melhor e, portanto, necessário, mas [...] com uma necessidade que não tira nada da liberdade porque não retira nada da vontade e do uso da razão. (LEIBNIZ, 1989, p. 147)

Leibniz, ao rejeitar a tese espinosana de que a existência de Deus e a existência de todas as coisas são caracterizadas pela mesma necessidade, pretende introduzir a noção de contingência sem a qual não é possível pensar a liberdade moral, nem em Deus, nem na criação. De fato, tal liberdade exige contingência, tanto na escolha do fim quanto da ação para atingi-lo. Consciente disso, Leibniz torna a contingência tema central e recorrente tanto nas obras sistemáticas - Discurso de Metafísica, Teodiceia e Monadologia - quanto em muitos opúsculos. No âmbito teológico da doutrina da criação, Leibniz deve superar dois problemas intrinsecamente vinculados (e mutuamente implicados) à afirmação de que este é o melhor 
dos mundos possíveis. A primeira se refere ao entendimento divino, como assegurar que este mundo seja contingente (ou seja, que ele seja um entre outros possíveis)? A segunda questão afeta à vontade. Sendo Deus bom e perfeitíssimo, não seria necessária a escolha do melhor mundo possível?

O primeiro problema evoca o conceito de verdade. Leibniz (2017, p. 356) rejeita como falsa a noção de liberdade isenta de necessidade, certeza e determinação, razão e perfeição. Leibniz defende que a noção de substância individual contém tudo quanto lhe possa acontecer. Qualquer predicado deve estar contido na noção de sujeito, ou seja, todo e qualquer evento é dotado de plena inteligibilidade a priori. Há textos que parecem sugerir uma fatalidade absoluta. É o que se constata quando se lê o ensaio Sobre o destino: "que tudo é produzido por um destino fixo é tão certo como três vezes três são nove. Pois o destino consiste em que tudo está mutuamente enlaçado como em uma cadeia, e é tão infalível o que ocorrerá, antes que ocorra, quanto é infalível o que ocorreu quando ocorreu" (LEIBNIZ, 1990, p. 13). Dessa forma, a verdade, definida como a inclusão do predicado ou consequente no sujeito ou antecedente, assume uma posição central na construção leibniziana do conceito de liberdade. Se todo consequente está contido no antecedente a priori, como explicar a liberdade? Na argumentação de Leibniz, a ação humana torna-se desdobramento predicamental do sujeito humano feito ideia (LEIBNIZ, 2004, p. 25). O desafio é conciliar presciência e liberdade (LEIBNIZ, 1970, p. 73). Leibniz conclui que a traição já estava contida na ideia de Judas. Ele assegura que a ação de Judas fora contingente e, portanto, livre, pois fundou-se no livre arbítrio de Deus - que o colocou na existência, escolhendo-o dentre outras possibilidades - e em seu próprio livre-arbítrio, cuja escolha tem razões, que, no entanto, inclinam sem necessitar (LEIBNIZ, 2004, p. 64).

Leibniz entende superar o necessitarismo por uma distinção no conceito de necessidade. Leibniz toma partido na famosa controvérsia entre Hobbes e Bramhall. Hobbes afirma que o efeito prova que as causas que o produziram eram suficientes para a sua produção e, portanto, necessárias. Bramhall, por sua vez, entende que Hobbes não prova a necessidade absoluta e antecedente, mas apenas uma necessidade hipotética. Nos termos em discussão, a necessidade hipotética significa que suposta a causa, o efeito se segue. A necessidade absoluta, por sua vez, implica que o evento, ou a ação efetuada, era necessário antes da concorrência das causas que o determinam (BRAMHALL, 1999, p. 52). Leibniz adota a distinção de Bramhall entre necessidade absoluta e necessidade hipotética. Ele entende que Hobbes não foi capaz de superar o necessitarismo por não caracterizar como distintos os âmbitos de jurisdição, embora universais, dos princípios de contradição 
e de razão suficiente. Por isso, tampouco distinguiria entre necessidade metafísica, dotada de caráter geométrico e aplicável apenas às verdades de razão, e a necessidade hipotética, aplicada à física e à moral. Enquanto o princípio de contradição se aplica ao entendimento divino, o princípio de razão suficiente presume o ato voluntário de Deus (LEIBNIZ, 2007, p.264).

No Discurso de Metafísica, Leibniz distingue, no âmbito do entendimento divino, onde opera o princípio de contradição, as noções abstratas e noções individuais. Tal distinção é considerada importantíssima por Leibniz, pois vislumbra por ela uma saída do labirinto necessitarista no qual se via cercado (LEIBNIZ, 1990, p. 98). As noções abstratas e as noções individuais encontram-se plenamente determinadas, mesmo se virtualmente, no entendimento divino. No entanto, enquanto as noções abstratas o são necessariamente e independentemente da vontade divina, as noções individuais passam a ser necessárias (necessária ex hypothesi) pelo decreto da vontade divina. Dito de outro modo, nessa esfera, é absolutamente necessário aquilo cujo contrário implique contradição. É, por exemplo, absolutamente necessário que três vezes três são nove. E o contrário disso é um nada. No entanto, aquilo cujo contrário não implique contradição é uma possibilidade (LEIBNIZ, 1998, p. 108). A noção completa de Alexandre implica sua vitória sobre Dario; visto que o contrário não comporta contradição, ambas são possibilidades no entendimento divino. Enquanto não se dá o decreto da vontade divina, as noções individuais seguem no entendimento divino como meras possibilidades. Na Confessio Philosophi, Leibniz esclarece que as proposições analíticas são necessárias e as proposições sintéticas, contingentes. Todo juízo verdadeiro de sujeito e predicado é analítico, isto é, o predicado forma parte da noção de sujeito, a menos que a existência real seja afirmada. "A existência, somente ela entre todos os predicados, não está contida na noção do sujeito que existe. As proposições existenciais, exceto no caso da existência de Deus, são sintéticas." (RUSSELL, 1900, p. 9). Isto é, não haveria contradição se os sujeitos que existem não existissem.

\begin{abstract}
Neste lugar chamamos necessário apenas aquilo que é necessário por si, ou seja, que tem a razão de sua existência e a verdade em si. Tais são as verdades geométricas, e das coisas existentes, somente Deus. As outras, que decorrem da suposição desta série de coisas - isto é, da harmonia das coisas - ou da existência de Deus, são contingentes por si mesmas e apenas hipoteticamente necessárias. (LEIBNIZ, 1970, p. 57)
\end{abstract}

Mas se Deus - o ser absolutamente necessário - escolhe necessariamente o melhor, como seria contingente o que é escolhido? A contingência da criação contraria um axioma incontroverso da lógica modal: se P é necessário, e P implica $\mathrm{Q}$ 
então Q é necessário. Tal axioma é frontalmente contestado por Leibniz na Confessio philosophi. Leibniz argumenta que de premissas necessárias pode decorrer conclusões contingentes. Por este argumento, Leibniz logra distinguir o conhecimento verdadeiro com certeza - o conhecimento infalível, porém contingente - e as verdades absolutamente necessárias. Fundamenta-se, dessa forma, a possibilidade lógica da compatibilização entre determinismo, contingência e liberdade da vontade.

Eu respondo que é falso que o que se segue do que é necessário em si, seja necessário em si. De verdades, com certeza, nada segue que não seja verdade. No entanto, visto que uma [conclusão] particular pode seguir-se de [premissas] puramente universais, como em [as figuras silogísticas] Darapti e Felapton, porque não pode algo que é contingente, ou necessário na hipótese de alguma outra coisa, decorrer de algo que é necessário em si? (LEIBNIZ, 1970, p. 55)

Na medida que os possíveis se articulam na mente divina, o princípio de contradição não implica apenas possibilidades isoladas, mas, sobretudo, compossibilidades e incompossibilidades. Logo, a criação, ato de vontade que estabelece a passagem da possibilidade à existência, levará em conta as articulações (compossibilidades, incompossibilidades) fundamentadas no princípio de contradição. Leibniz logra encontrar possibilidades que justificam incontáveis mundos possíveis e fundamentam a contingência no nível do entendimento divino. De fato, se não houvesse incompossibilidade, tudo seria absolutamente necessário. Pelos "possíveis" Leibniz resgatou a possibilidade de um discurso teleológico. Deus elege um fim e escolhe livremente dentre as várias possibilidades o melhor meio de realizá-lo. Em Leibniz suficiência não se identifica com eficiência, e tem acento teleológico. Enquanto em Hobbes a razão está empenhada na compreensão racional dos eventos físicos, em Leibniz, o acento está sobre a fundamentação racional do mundo. Se Leibniz se apropria da causalidade mecânica de Hobbes é para submetê-la a uma determinação essencialmente teleológica da realidade (HIRATA, 2012, p. 109-120).

Leibniz pressente a necessidade de atribuir aos possíveis um estatuto ontológico; do contrário, não teria logrado mais que provar que o real não esgota as possibilidades lógicas. Os possíveis teriam caráter meramente mental e, portanto, fictício. Por isso Leibniz é levado a introduzir os possíveis como representações no intelecto divino, cujo conteúdo é assumido como eternamente consistente e isento de contradição. No entanto, o estatuto ontológico dos possíveis implica novos problemas para a consolidação da contingência. Se considerarmos que, para Leibniz, todos os possíveis tendem a existir e a razão pela qual Deus não os pôs todos na 
existência deve residir na incompossibilidade; isso significa que, independentemente da vontade de Deus, a existência de uns torna inexequível a existência de outros (MARQUES, 2004). O estatuto ontológico dos possíveis parece autonomizar os requisitos de existência. Em Sobre a existência (1676) afirma Leibniz: "existir, para uma coisa, é idêntico a ser concebido por Deus como o melhor, ou seja, como o mais harmônico" (LEIBNIZ, 1998, p. 30). Então, existir significa o mesmo que uma definição real de existência, a saber, existe o que é maximamente perfeito dentre aquelas coisas que poderiam existir, o que envolve mais essência.

Atribuir significado ontológico a possibilidades que não teriam os requisitos de existência parece uma ficção ontológica. Trata-se de uma tese metafísica de significado esfíngico. Para que os eventos e substâncias intramundanos sejam contingentes basta que os meramente possíveis tenham algum estatuto ontológico. Não está claro em que sentido conferir estatuto ontológico aos possíveis possíveis que não existem, jamais existiram e nunca existirão - seja suficiente para evitar o necessitarismo. Pois é o mesmo que afirmar que todo possível deve ser necessariamente meramente possível. Contudo, esse já não é um problema relacionado ao entendimento divino. O estatuto ontológico dos possíveis redunda no flagrante esvaziamento do ato de vontade. Se a existência se define pelo nível de perfeição das essências, então o mundo existe por definição, como resultado de um cálculo lógico, sem necessidade de decreto. Leibniz se vê num labirinto, para assegurar estatuto ontológico para os possíveis (sem os quais não haveria contingência), ele dissolve a noção de criação e o próprio ato de vontade divina.

A questão aprofunda-se ao analisarmos o princípio de razão suficiente, que vigora no ato de vontade divina. O princípio de razão suficiente implica que "nenhum fato pode ser verdadeiro ou existente e nenhum enunciado verdadeiro, sem que haja uma razão suficiente" (LEIBNIZ, 2004, p.137). O princípio de razão suficiente não admite que a indiferença seja condição de possibilidade para a liberdade. Antes, a indiferença representa um impasse que deveria ser rompido por um ato de escolha desmotivado. É famosa a ilustração, na correspondência com Clarke, do princípio de razão suficiente pela balança de Arquimedes. "Se há uma balança em que tudo seja igual de ambas as partes, suspendendo-se também pesos iguais nas extremidades dessa balança, ela ficará em repouso" (LEIBNIZ, 1980a, p. 57). Ou seja, é necessário que haja um fundamento de determinação qualquer; pois ainda que as razões se equivalessem, as paixões não se igualariam. O exemplo de Leibniz não é feliz, pois identifica o agente com uma balança passiva. Tal passividade parece anular a vontade, completamente identificada com a razão ou motivo determinante(LEIBNIZ, 1990, p. 178-179). 
A passividade da balança parece ser um eco inapropriado do mecanicismo. De fato, para Leibniz, o mecanicismo não se opõe ao princípio teleológico; pelo contrário, na medida em que postula a passividade dos corpos, exige que um princípio espiritual seja a origem deles e de seu movimento. No entanto, a relação entre o mecanicismo e a liberdade humana demanda sem dúvidas esclarecimentos. A aplicação do princípio de razão suficiente ao ato criador de Deus parece, exatamente como no exemplo da balança, identificar a harmonia do melhor mundo possível - pois indiferença e o princípio de razão suficiente se excluem mutuamente - com a vontade divina, suplantando-a. Ademais, a própria noção de possibilidade parece ter sua efetividade mitigada pela afirmação de que as coisas são necessariamente na medida em que reúnem todos os requisitos de existência.

Consciente dessas dificuldades, Leibniz, sobretudo no Discurso de Metafísica e na Correspondência com Arnauld, trabalha para reforçar o papel da vontade divina para assegurar a liberdade. No Discurso de Metafísica, Leibniz propõe que o primeiro decreto livre que Deus estabeleceu foi fazer sempre o mais perfeito. Leibniz assegura de uma só vez a efetividade e a liberdade da vontade divina e da vontade humana sem abrir mão da certeza e da contingência de suas opções.

Embora seja razoável e seguro que Deus fará sempre o melhor, embora o que é menos perfeito não implique contradição, ver-se-ia não ser tão absoluta como a dos números ou da geometria a demonstração deste predicado de César, mas que supõe a série de coisas livremente escolhidas por Deus, e que está fundada sobre o primeiro decreto livre divino, que estabelece fazer sempre o mais perfeito, e sobre o decreto feito por Deus (depois do primeiro) a propósito da natureza humana, ou seja: que o homem fará sempre, embora livremente, o que lhe parece melhor. Ora, toda verdade fundada nesses tipos de decreto é contingente, apesar de certa; porque esses decretos não mudam a possibilidade das coisas e, como já disse, ainda que Deus seguramente escolhesse sempre o melhor, tal não impede o que é menos perfeito de ser e continuar possível em si, embora não aconteça, porque não é sua impossibilidade, mas sim sua imperfeição, que o faz rejeitar. (LEIBNIZ, 2004, p.27)

A essa altura alcançamos uma profundidade ulterior do problema: a contingência da escolha divina. O mundo atual é contingente, pois é escolhido dentre outras compossibilidades não contraditórias. Mas, uma vez que Deus é perfeitíssimo, decorreria necessariamente (sem contingência e, portanto, sem liberdade) a escolha pelo melhor? Sendo perfeitíssimo, poderia Deus não optar pelo melhor? Os intérpretes apontam duas possibilidades, que não se excluem mutuamente, para a solução do problema: ou é contingente que este mundo seja o melhor, ou é contingente que Deus escolha o melhor (ADAMS, 1994, p. 23; OLIVA, 2006, p. 60). Há textos de Leibniz corroborando ambas possibilidades. 
Por um lado, Leibniz trabalha a noção de que seja indemonstrável que esse mundo seja o melhor. Ora, visto que só é necessário aquilo cujo contrário seja redutível à contradição, o que não é possível para a noção do mundo real, então temos de reconhecer que a afirmação de que este mundo é o melhor dos mundos possíveis é contingente (pois sua necessidade é indemonstrável). Logo, ainda que seja necessária a proposição de que Deus quer necessariamente o melhor mundo possível, não seria necessária a proposição de que este é necessariamente o melhor.

Devemos ver se supomos que esta proposição é necessária: a proposição que tem a maior razão para a existência existe, segue-se que a proposição que tem maior razão para existir é necessária. Mas a inferência é corretamente rejeitada. Pois se a definição de uma proposição necessária é, que sua verdade pode ser demonstrada com rigor geométrico, então pode realmente acontecer que esta proposta possa ser demonstrada: toda verdade, e somente a verdade, tem a maior razão, ou esta: Deus age sempre da forma mais sábia. Mas não será possível demonstrar essa proposição: A proposição contingente A tem uma maior razão ou a proposição contingente A é conformada pela divina sabedoria. E, portanto, também não se segue que a proposição contingente A seja necessária. E, portanto, mesmo que se admitisse que é necessário que Deus escolha o melhor, ou que o melhor é necessário, ainda assim não se segue que o que é escolhido seja necessário, uma vez que não se pode demonstrar. (LEIBNIZ, 1948, p. 305)

Nesse caso, o entendimento divino, perfeitíssimo, "conhece" necessariamente o contingentemente (pois não se trata de uma necessidade cujo contrário seja redutível à contradição) melhor mundo possível. Logo, quando a vontade divina quer necessariamente o melhor, o conteúdo querido (o melhor mundo possível) não é mais que uma noção contingente. Este argumento é passível de críticas e não as aprofundaremos aqui. Basta-nos reconhecer que a indemonstrabilidade de que este mundo seja o melhor só se pode referir a um intelecto finito, não ao divino. O entendimento divino não poderia apresentar à vontade divina um mundo que não fosse necessariamente o melhor, ainda que tal necessidade não fosse geométrica. O conhecimento perfeitíssimo de Deus homogeneíza (simplifica) de alguma forma a distinção entre verdades de razão e verdades de fato. A questão que se impõe é: até que ponto a noção de contingência lógica é suficiente para assegurar a contingência moral?

Se não fosse o melhor em si ou em relação ao fim, a escolha de Deus infringiria o princípio de razão suficiente. Então, muitos intérpretes avaliaram a possibilidade de Leibniz considerar que a bondade divina não fosse necessária. Apresentou-se como argumento o fato de no início do Discurso de Metafisica, ao tratar da perfeição divina, ele apresente apenas os atributos da máxima ciência e da onipotência, sem referir-se à bondade (LEIBNIZ, 2004, p. 3). No entanto, não faltam 
textos nos quais Leibniz insere a bondade entre as perfeições divinas (LEIBNIZ, 2004, p. 139-140). A vontade e a bondade de Deus são idênticas. "A vontade consiste na inclinação a fazer algo proporcionalmente ao bem que ele encerra" (LEIBNIZ, 2017 , p. 148). De fato, “a vontade é proporcional ao sentimento que nós temos do bem, e disso segue a predominância" (LEIBNIZ, 2017, p. 337). A vontade divina "quer antecedentemente o bem e, consequentemente, o melhor" (LEIBNIZ, 2017, p. 149). Ou seja, a vontade é antecedente quando considera os bens isoladamente, cada bem enquanto bem, e é dita consequente, quando é o resultado do conflito de todas as vontades antecedentes (tanto daquelas que tendem ao bem quanto daquelas que resistem ao mal), a vontade total (LEIBNIZ, 2017, p. 148). Então é necessário que a vontade divina, assim como a humana, se dirija ao bem e tanto melhor, maior a vontade (OLIVA, 2006, p. 77). Mas, se a bondade de Deus é metafisicamente necessária, em que se distinguiria Leibniz do espinosismo?

Parece que a solução para o problema é a distinção entre a bondade necessária da vontade divina e a escolha necessária do melhor mundo possível. Leibniz conclui que embora a vontade divina seja boa por natureza, ou seja, necessariamente, as coisas não existem necessariamente, pois não existe contradição no fato de a vontade divina ter possibilidades que lhe são contrárias (incluindo a possibilidade de nada criar). Uma vez mais Leibniz faz uso dos possíveis, dessa vez para fundamentar a contingência da escolha divina. Com isso, Leibniz quer evitar tanto o determinismo absoluto, segundo o qual existe tudo quanto é possível, quanto o voluntarismo, que faz o mundo existir por arbitrariedade divina.

Deus não faz o melhor necessariamente, mas porque quer: quem me perguntasse se Deus quer necessariamente, teria de explicar previamente a que tipo de necessidade se refere ou então colocar a questão mais amplamente, perguntando, por exemplo, se Deus quer necessariamente ou livremente, isto é, em virtude de sua natureza ou de sua vontade. A meu modo de ver, Deus não pode querer voluntariamente, pois de outro modo se daria a vontade de querer ao infinito. Mas há de se afirmar que Deus quer o melhor devido a sua própria natureza. Logo quer necessariamente, dir-se-á. Trata-se de uma feliz necessidade, dir-se-á com santo Agostinho. Daí se deduzirá que as coisas existem de modo necessário. Por quê? Por que implica contradição que não exista o que Deus quer? Nego que esta proposição seja absolutamente verdadeira. De outro modo tudo o que Deus não quer não seria possível. Quando em realidade continua sendo possível, embora não escolhido por Deus. Pois é possível existir aquilo que Deus não quer que exista, já que poderia existir por sua natureza se Deus quisesse que existisse (LEIBNIZ, 1990, p. 8-9).

Dessa forma, a proposição segundo a qual "uma pessoa é moralmente responsável pelo que ela fez somente se pudesse ter feito de outro modo" se aplica a Deus em dois sentidos fundamentais. Deus é dotado de liberdade metafísica, no 
sentido que não pode sofrer nenhum tipo de demanda ou constrangimento exterior nem para criar nem para atuar no mundo criado (espontaneidade). Por outro lado, Deus é isento de paixões, o que lhe assegura ausência de coação interna. Ou seja, o princípio de razão suficiente não significaria uma coação intelectual que suprime o ato de vontade, pois também nesse caso dá-se uma inclinação que não necessita. De fato, a mera ausência de coação externa não asseguraria que o homem estivesse livre, pois sempre haveria a possibilidade de estar sob o efeito de paixões ou coações incontroláveis. No entanto, isso não se aplica a Deus, pois n'Ele as paixões não se sobrepõem à razão (LEIBNIZ, 1980, p. 125-126). Portanto, Deus cria livremente, escolhendo dentre as inúmeras possibilidades, o melhor dos mundos possíveis. Os possíveis parecem indispensáveis à noção de contingência tanto na ordem do entendimento quanto na ordem da vontade divina.

\subsection{A LIBERDADE HUMANA: AUTOMATISMO ESPIRITUAL E CONTINGÊNCIA}

Os princípios desenvolvidos por Leibniz e aplicáveis a Deus na defesa de sua liberdade e de seus atributos, sobretudo, a sabedoria e a bondade, fundamentam a liberdade humana. Em Leibniz, a alma (e sua inteligência e vontade) é autônoma, o que se vincula imediatamente à noção de espontaneidade. A espontaneidade não é apresentada por Leibniz como uma novidade conceitual, ele mesmo se refere a Aristóteles (LEIBNIZ, 2017, p. 339). Para compreendermos a espontaneidade leibniziana, é preciso interpretá-la no marco da sua monadologia. Para Leibniz, toda mônada exprime o universo por suas ações internas e imanentes e não é concebível que uma mônada atue sobre as demais ou sofra qualquer influxo delas. Leibniz pensa a atuação da alma como autônoma em relação ao corpo e em relação a todas as outras mônadas (LEIBNIZ, 2004, p. 40). Os objetos externos e sensíveis, mesmo o próprio corpo, não podem agir imediatamente sobre a alma. Eis o fundamento ontológico sobre o qual Leibniz apoia a noção de espontaneidade. A espontaneidade é propriedade de todas as mônadas, logo não afeta exclusivamente o homem. Cada mônada é, em virtude deste princípio interno, um microcosmo autárquico, visto que nenhuma causa externa poderia influir nos processos e mudanças naturais da mônada. E visto que todas as suas ações procedem de sua profundidade ontológica, tudo se encontra nela a priori. Segue-se que as mudanças naturais das mônadas vêm de um princípio interno, já que uma causa externa não poderia influenciar o seu interior (LEIBNIZ, 2004, p. 41). Todas as mônadas são enteléquias, pois são "fontes das suas ações internas e por assim dizer autômatos incorpóreos" (LEIBNIZ, 2004, p. 134). 
A autonomia e espontaneidade ontológica redunda em autonomia e espontaneidade ética. As razões do entendimento - e não as tendências de uma sensibilidade exterior à alma - subordinam a vontade. Por decreto da vontade divina, o entendimento orienta a vontade para o bem aparente, para o qual a vontade tende sem ser necessitada. Tal convicção é tão sólida, que Leibniz pressentiu a necessidade de afirmar que as razões do entendimento humano não impedem que o ato da respectiva vontade seja contingente (LEIBNIZ, 1980, p.126). Leibniz, em Textes inédits, consolida a distinção entre necessidade e determinismo. O caráter determinado e absolutamente certo qualifica a ação voluntária.

\begin{abstract}
Mas se não há necessidade absoluta nas coisas passageiras, é preciso sempre confessar que tudo aí é absolutamente certo e determinado. E a determinação não é uma necessidade, mas uma inclinação maior sempre ao que acontecerá que ao que não acontecerá, de sorte que se pode dizer que há sempre a mesma proporção entre a necessidade e a inclinação que há na análise dos matemáticos entre a equação exata e os limites que dão uma aproximação [...] E além disso, no mundo cada causa é determinada a produzir um tal efeito com tais circunstâncias, e mesmo somos determinados a tomar o partido para o qual tende mais a balança da deliberação, na qual entram as razões verdadeiras e falsas, tanto quanto as paixões. E é então que nossa ação é voluntária, de outro modo ela é indeliberada. Assim, embora estas determinações propriamente falando não necessitem, elas não deixam de inclinar, e nós seguimos sempre o partido em que há mais inclinação ou disposição. (LEIBNIZ, 1948, p. 479)
\end{abstract}

Leibniz assegura que "a vontade está na indiferença desde que se oponha à necessidade, e tem o poder de proceder diversamente ou ainda de suspender de todo a sua ação, pois ambos os partidos são e continuam possíveis" (LEIBNIZ, 2004, p. 63). Não se pode, no entanto, pensar que Leibniz faça uma concessão à liberdade de indiferença em sentido próprio, já claramente negada (LEIBNIZ, 2017, p. 163). O que ele quer enfatizar, na verdade, é que a vontade segue livre, apesar da determinação do entendimento a respeito do bem aparente, objeto da vontade. Leibniz insiste na contingência da escolha humana.

Eu sou da opinião de que nossa vontade não apenas é isenta da coação, mas, além disso, da necessidade. Aristóteles já observou que há duas coisas na liberdade, a saber, a espontaneidade e a escolha; e é nisso que consiste o nosso domínio sobre nossas ações. Quando agimos livremente, não somos forçados, como aconteceria se fôssemos empurrados em direção a um precipício e fôssemos jogados do alto para baixo; não somos impedidos de ter o espírito livre quando deliberamos, como aconteceria se nos fosse dada uma bebida alcoólica que tirasse nossa capacidade de julgar. Existe contingência nas incontáveis ações da natureza; mas quando o julgamento não está naquele que age, não existe liberdade. E se tivéssemos um julgamento que não fosse acompanhado de alguma inclinação para agir, nossa alma seria um entendimento sem vontade (LEIBNIZ, 2017, p. 155-156). 
A inteligência exerce função capital no uso da liberdade. Leibniz se insere na tradição agostiniana para a qual liberdade e livre-arbítrio são coisas distintas. Embora o livre arbítrio seja condição inexcusável da liberdade, não se identifica com ela. A liberdade só se fará presente quando se atue conforme à razão. A liberdade consiste, pois, no bom uso do livre arbítrio e só tem lugar quando o conhecimento racional do bem se converte em motivo determinante da ação. Só a vontade determinada a partir de um conhecimento distinto está isenta da escravidão. No entanto, a alma, criatura imperfeita, contém em si paixões, que conduzem a pensamentos confusos e determinam a vontade a escolher entre males (LEIBNIZ, 1980, p. 142).

Nosso conhecimento é de dois tipos, distinto ou confuso. O conhecimento distinto ou a inteligência tem lugar no verdadeiro uso da razão; mas os sentidos nos fornecem pensamentos confusos. E podemos dizer que estamos isentos da escravidão enquanto agimos a partir de um conhecimento distinto; mas que estão sujeitos às paixões enquanto nossas percepções são confusas. É nesse sentido que não temos toda a liberdade de espírito que seria de desejar, e que podemos dizer com santo Agostinho, que estando sujeito ao pecado, nós temos a liberdade de um escravo. Todavia, um escravo, qualquer que seja o escravo, não deixa de ter a liberdade de escolher em conformidade com o estado em que se encontra, embora se encontre o mais frequentemente na obrigação de escolher entre dois males, porque uma força superior não o deixa alcançar os bens aos quais aspira. E o que as correntes e a coerção provocam em um escravo é provocado em nós graças as paixões, cuja violência é doce, mas não é menos perniciosa. Na verdade, só queremos aquilo que nos agrada, mas, infelizmente, o que nos agrada no presente é frequentemente um verdadeiro mal, que nos desagradaria se tivéssemos os olhos do entendimento abertos. No entanto, essa má condição em que se encontra o escravo, e aquela em que nos encontramos, não impede que, na condição a qual estamos reduzidos, façamos uma escolha livre (tanto quanto ele) daquilo que nos agrada, mas conforme nossas forças e nosso conhecimento presente. (LEIBNIZ, 2017, p. 338)

Chama, pois, atenção que Leibniz sugira a existência de ações que não se realizam através da vontade, identificando-a com o motivo conforme à razão (LEIBNIZ, 2017, p. 156). Leibniz entende que "o espírito não tem poder completo e direto para sempre bloquear os seus desejos" (LEIBNIZ, 1980, p. 139). No entanto, Leibniz distingue nitidamente entre vontade e razão. Tal distinção se faz clara pelo modo diverso como a inteligência influencia a vontade na escolha do querer e na escolha das ações. Enquanto na escolha da ação a influência é imediata, na escolha do querer a influência é mediata. Ou seja, somente mediante a reflexão podemos determinar a vontade a querer no futuro como julgamos que ela deveria querer no presente.

Tudo o que acontece à alma depende dela, mas não depende sempre de sua vontade; isso seria demais. Não é de fato sempre conhecido ou apercebido distintamente por seu entendimento. Pois nela há não apenas uma ordem de percepções distintas que 
faz seu domínio, mas também uma sequência de percepções confusas ou de paixões, que ocasiona sua escravidão, e não é preciso estranhar isso; a alma seria uma divindade, se ela tivesse apenas percepções distintas. Ela tem, no entanto, algum poder também sobre essas percepções confusas, mesmo que de uma maneira indireta; pois embora ela não possa mudar suas paixões prontamente, ela pode trabalhar nisso com considerável antecedência e bastante sucesso, e se dar novas paixões, e mesmo (novos) hábitos. Ela tem até um poder semelhante sobre as percepções mais distintas, podendo se dar indiretamente opiniões e vontades, e se impedir de ter estas ou aquelas e suspender ou emitir seu julgamento (LEIBNIZ, 2017, p. 172).

Leibniz adere à noção lockiana de inquietação presente como fator determinante da vontade em senso lato. Elas distinguem-se das inclinações e paixões por seu caráter inconsciente. A noção de percepções insensíveis está à serviço da lei da continuidade aplicada ao plano psicológico, ou seja, "uma substância não pode estar sem ação, e jamais existem corpos sem movimento", o que atende plenamente à negação do conceito de indiferença da vontade (LEIBNIZ, 1980, p. 7). Leibniz distingue a inquietação das inclinações e paixões (LEIBNIZ, 1980, p. 118). O conceito de percepções insensíveis serve para explicar uma série de fenômenos: a convergência de tudo, a constituição do próprio indivíduo e as inquietações que determinam a vontade encontram sua fundamentação nas percepções inconscientes, inclusive a união pré-estabelecida. Essas percepções, que Leibniz qualificou 'insensíveis' e 'pequenas', por não provocarem qualquer sentimento consciente na alma, se identificam com a infinidade de pequenas inclinações e disposições de minha alma, presentes e passadas, que entram na sua causa final. Dessa forma, ao introduzir um componente inconsciente na teoria da ação, Leibniz sepulta definitivamente a doutrina da indiferença de equilíbrio da vontade e a impressão de que temos diante de nós um futuro aberto.

De resto, existe uma série de indícios que nos autorizam a crer que existe a todo momento uma infinidade de percepções em nós, porém sem apercepção e sem reflexão: mudanças na própria alma, das quais não nos apercebemos, pelo fato de as impressões serem ou muito insignificantes e em número muito elevado, ou muito unidas, de sorte que não apresentam isoladamente nada de suficientemente distintivo; porém, associadas a outras, não deixam de produzir o seu efeito e de fazer-se sentir ao menos confusamente [...] Essas percepções insensíveis assinalam também e constituem o próprio indivíduo, que é caracterizado pelos vestígios ou expressões que elas conservam dos estados anteriores deste indivíduo, fazendo a conexão com o seu estado atual, percepções que se podem conhecer por um espírito superior, mesmo que este indivíduo não as pudesse sentir, isto é, quando a recordação explícita não estivesse mais presente [...] É também pelas percepções insensíveis que se explica esta admirável harmonia preestabelecida da alma e do corpo, e mesmo de todas as mônadas ou substâncias simples, que substitui a influência insustentável de uns sobre os outros, harmonia que, no pensar do autor do mais belo dos dicionários, enaltece a grandeza das perfeições divinas além de tudo o que se tenha jamais concebido. Depois disso acrescentaria pouca coisa se dissesse que são essas pequenas percepções 
que nos determinam em muitas ocasiões sem que pensemos, e que enganam o homem vulgar pela aparência de uma indiferença de equilíbrio, como se fosse para nós completamente indiferente (para dar um exemplo) voltarmos à direita ou à esquerda. (LEIBNIZ, 1980, p. 7-9)

Embora Leibniz trate de mecanismos inconscientes em sua teoria da ação, sobretudo referindo-se a mecanismos instintivos, toda ação humana com pretensão moral ocorre sob o império da razão (LEIBNIZ, 2017, p. 359-360). A alma tem poder sobre suas inclinações, mesmo se tal poder se exerça indiretamente. As ações externas, que não ultrapassam nossas forças, dependem absolutamente de nossa vontade. No entanto, as apetições não dependem da vontade, exceto por hábeis artifícios que nos dão os meios de suspender nossas decisões ou de modificálas (LEIBNIZ, 2017, p. 360). Tal atuação sobre si, se exprime melhor pelos termos consciência ou reflexão. Na reflexão, sujeito e objeto coincidem. No entanto, a consciência não implica apenas a presença atual, mas comporta também a memória - que assegura ao homem identidade e percepção de totalidade e duração - e a dimensão prática. Além disso, a consciência pensa distintamente os objetos e circunstâncias que nos afetam. Ou seja, a consciência é simultaneamente psicológica, intencional e moral.

A complexa hierarquia perceptiva da doutrina leibniziana do conhecimento puramente obscuro até o adequado, corresponde a uma também complexa rede afetiva na qual se entrelaçam inclinações, inquietudes, prazeres e dores determinando a vontade. Nesse contexto, a inteligência assumirá a função decisiva de determinar a vontade na direção do verdadeiro bem, nisso consistirá a liberdade em seu sentido pleno, uma vez que o mero arbítrio - ainda mais quando se escolhe entre bens inferiores - não representa adequadamente a liberdade.

A liberdade de arbítrio e, por conseguinte, a liberdade de ação são concebidas na conciliação do determinismo com a contingência, sintetizadas no princípio de razão suficiente. Tudo o que acontece, incluindo as moções celestiais, a formação das plantas e o corpo dos animais, assim como os processos da vida são regulados por leis mecânicas como o movimento dos ponteiros são controlados em um relógio. Não há influência de uma substância sobre outra, nem do corpo sobre a alma ou vice-versa, mas tudo concorda pelas leis ordinárias do mundo estabelecidas por Deus. Tal concordância no homem, entre a alma e o corpo, se revela na união preestabelecida (LEIBNIZ, 2004, p. 137). Uma vez que o mundo é o resultado de um decreto divino, através dos processos mecânicos se realiza um processo teleológico. Leibniz integra "o reino do poder ou das causas eficientes" ao "reino da sabedoria ou das causas finais" (cf. MCDONOUGH, 2008). Donald Rutherford observou a existência de duas concepções de teleologia: a tendência da mônada para 
um estado de coisas objetivamente ótimo e a tendência da mônada para um estado de coisas meramente percebido ou aparentemente ótimo. Rutherford, distingue entre as "leis da teleologia natural", aplicáveis a todas as mônadas, e as "leis da teleologia desejada", aplicáveis somente às mônadas dotadas de inteligência e vontade (RUTHERFORD, 2005, p. 166-169). Essa distinção sublinha o caráter peculiar das mônadas dotadas de inteligência e vontade e de seu modo de realização teleológica.

O homem leibniziano, representado na tensão entre a necessidade e a contingência, é definido como autômato espiritual. A noção de espontaneidade deve ser compreendida no âmbito da noção de necessidade hipotética. Como aponta Colchan Roldán Panadero, Leibniz chama muitas vezes a liberdade de "espontaneidade inteligente", "espontaneidade racional" ou "espontaneidade consultante" (ROLDÁN, 1990, p. XLVII). À espontaneidade Leibniz incorpora a contingência no enquadramento da necessidade hipotética. A contingência emerge nesse contexto teórico como conceito essencial à concepção da liberdade.

Tudo é, então, antecipadamente certo e determinado no homem, como em qualquer lugar; e a alma humana é uma espécie de autômato espiritual, embora as ações contingentes em geral, e as ações livres em particular, não sejam por isso necessárias a partir de uma necessidade absoluta, a qual seria verdadeiramente incompatível com a contingência. Portanto, nem a futuração (futurition) em si mesma - por mais certa que seja -, nem a previsão infalível de Deus, nem a predeterminação das causas, nem a dos decretos de Deus destruiriam essa contingência e essa liberdade (LEIBNIZ, 2017, p. 164-165).

\section{CONSIDERAÇÕES FINAIS}

Leibniz não pôde admitir que a liberdade fosse pensada nos termos meramente mecânicos com que Hobbes a associa ao fluxo da água. Leibniz não se limita à demonstração da insuficiência do mecanicismo como fundamento lógico e ontológico para um conceito moral de liberdade. O universo autômato é regido por um princípio espiritual que explica o movimento dotado de finalidade, o que extrapola o princípio de inércia que rege os corpos. Dessa forma, Leibniz logra distinguir, sobretudo em termos lógicos, o determinismo e o necessitarismo. Coube a Leibniz a tentativa de compatibilizar determinismo e liberdade da vontade por meio da contingência. Leibniz rechaça de modo consistente o necessitarismo e a redução do problema do livre arbítrio ao problema da livre ação.

O princípio de possibilidades alternativas [uma pessoa é moralmente responsável pelo que fez somente se pudesse ter feito de outro modo] é compatível com a noção leibniziana de liberdade, tanto humana quanto divina. A centralidade 
da inteligência no conceito de liberdade implica a desconexão da semântica mecanicista. Se na esfera teológica os possíveis e o decreto divino de que sua vontade escolherá sempre o melhor são indispensáveis à contingência; no âmbito antropológico, é importantíssimo o fato de a inteligência influenciar a vontade tanto na escolha das ações quanto na escolha do querer. Pela reflexão podemos determinar a vontade a querer no futuro como julgamos que ela deveria querer no presente.

Apesar dos longos argumentos em função da contingência tanto para os conteúdos do entendimento divino quanto para os decretos da vontade criadora, apesar da insistência sobre o fato de a vontade humana ser inclinada e não necessitada, a liberdade leibniziana é aporética. mecanicismo e teleologia, determinismo e contingência, automatismo e autonomia estão em permanente tensão no conceito leibniziano de liberdade. É persuasiva a distinção entre os âmbitos de atuação do princípio de não contradição e do princípio de razão suficiente. Mas, na medida em que nos afastamos do âmbito lógico em direção ao âmbito moral, as tensões aporéticas assumem contornos insustentáveis. Tem-se a impressão de que basta que a contingência assegure o mínimo necessário à teleologia. Como é possível falar de opção quando se trata de um autômato espiritual? Para Kant, a liberdade leibniziana é uma ilusão.

Se as ações do homem, da maneira como pertencem às suas determinações no tempo, não fossem simples determinações dele enquanto fenômeno, mas enquanto coisa em si mesma, a liberdade não se salvaria. O homem seria uma marionete ou um autômato de Vaucanson, fabricado e posto em movimento pelo mestre supremo de todas as obras de arte; e a consciência de si fá-lo-ia certamente um autômato pensante, no qual, porém, a consciência de sua espontaneidade, se fosse tomada pela liberdade, seria um simples engano, enquanto ela apenas comparativamente merece ser chamada assim, porque as causas determinantes próximas de seu movimento e uma longa série delas, em verdade, são internas, mas a última e suprema é encontrada totalmente em mão estranha. (KpV A, 181)

A crítica de Kant tem fundamento, mas não se pode falar em fracasso da teoria leibniziana. A tentativa de alojar as estruturas fundamentais do querer nos interstícios do determinismo mecanicista comporta a insolubilidade de alguns problemas e a limitação estrutural do discurso sobre a liberdade. Leibniz tem o mérito de realizar uma inversão na colocação do problema: trata-se, então, de saber como alojar o mecanicismo nas estruturas do querer teleológico de Deus. E isso repercute decisivamente sobre o modo de conceber a liberdade do homem.

\section{REFERÊNCIAS}

ADAMS, Robert. Leibniz: determinist, theist, idealist. Oxford: Oxford University Press, 1994. 
BOTTERILL, George. Hume on Liberty and Necessity. In: MILLICAN, P. Reading Hume on Human Understanding. Oxford: Clarendon Press, 2002.

BRAMHALL, Jhon. A Defence of True Liberty. In: CHAPPEL, Vere. Hobbes and Bramhall on Liberty and Necessity. Massachusetts: Cambridge University Press, 1999.

BRAMHALL, Jhon. Bramhall's discourse of liberty and necessity. In: CHAPPEL, Vere. Hobbes and Bramhall on Liberty and Necessity. Massachusetts: Cambridge University Press, 1999.

FRANKFURT, Harry G. Alternative Possibilities and Moral Responsibility. The Journal of Philosophy, Vol. 66, No. 23. (Dec. 4, 1969), pp. 829-839.

HIRATA, Celi. Leibniz e Hobbes: causalidade e princípio de razão suficiente. Tese doutoral. Faculdade de Filosofia, Universidade de São Paulo São Paulo: p. 262, 2012.

HOBBES, Of Liberty and Necessity. In: CHAPPEL, Vere. Hobbes and Bramhall on Liberty and Necessity. Massachusetts: Cambridge University Press, 1999.

HOBBES, Leviatã ou matéria, forma e poder de uma república eclesiástica e civil. Tradução: João Paulo Monteiro e Maria Beatriz Nizza da Silva. São Paulo: Martins Fontes, 2003.

HOBBES, British Moralists 1650-1800. Vol. 1. D.D. Raphael. Indiana: Hackett Publishing Company, 1991.

HUME, David. An Enquiry Concerning Human Understanding and Other Writings. Cambridge: Cambridge University Press, 2007.

HUME, David. Tratado da Natureza Humana. Uma tentativa de introduzir o método experimental de raciocínio nos assuntos morais. Tradução: Déborah Danowsk. São Paulo: Editora Unesp, 2001.

KANE, Robert. Acting of one's own free will: modern reflections on an ancient philosophical problem. Proceedings of the Aristotelian Society, Volume 114, Issue 1, April 2014, pp. 35-55.

KANT, Immanuel. Crítica da Razão Prática. Tradução, introdução e notas de Valério Rohden. Edição bilíngue. São Paulo: Martins Fontes, 2003.

LOCKE, John. An Essay Concerning Human Understanding. Londres: Printed by Eliz. Holt, 1690.

LOCKE, John. Ensaio Acerca do Entendimento Humano. Tradução de Anoar Aiex. São Paulo: Editora Nova Cultural, 1999.

LEIBNIZ, Gottfried Wilhelm. Confessio Philosophi - La profession de foi du Philosophe. Paris: Ed. Vrin, 1970.

LEIBNIZ, Gottfried Wilhelm. Conversación con el obispo Stenon acerca de la libertad. In: Escritos em torno a la libertad, el azar y el destino. Traducción de Roberto Rodrigues Aramayo y Concha Roldán Panadero. Madrid: Editorial Tecnos, 1990. 
LEIBNIZ, Gottfried Wilhelm. Del Destino. In: LEIBNIZ, Gottfried Wilhelm. Escritos en torno a la libertad, el azar y el destino. Traducción de Roberto Rodrigues Aramayo y Concha Roldán Panadero. Madrid: Editorial Tecnos, 1990.

LEIBNIZ, Gottfried Wilhelm. Discurso de Metafísica. In: Discurso de metafísica e outros textos. Tradução de Marilena Chauí. São Paulo: Martins Fontes, 2004.

LEIBNIZ, Gottfried Wilhelm. Ensaios de teodiceia sobre a bondade de Deus, liberdade do homem e a origem do mal. Tradução e notas de Willian Siqueira Piauí e Juliana Cecci Silva. São Paulo: Estação Liberdade, 2017.

LEIBNIZ, Gottfried Wilhelm. Novos ensaios sobre o entendimento humano. Tradução de Luiz João Baraúna. São Paulo: Abril Cultural, 1980.

LEIBNIZ, Gottfried Wilhelm. Os Princípios da Filosofia ou a Monadologia. In: Discurso de metafísica e outros textos. Tradução de Alexandre da Cruz Bonilha. São Paulo: Martins Fontes, 2004.

LEIBNIZ, Gottfried Wilhelm. Reflexões sobre a obra que o sr. Hobbes publicou em inglês, sobre a liberdade, a necessidade e o acaso. Trans/Form/Ação, São Paulo, 30(2), 2007, pp. 261-272.

LEIBNIZ, Gottfried Wilhelm. Réfutation inédite de Spinoza par Leibniz. Paris: A. Foucher de Careil, 1854.

LEIBNIZ, Gottfried Wilhelm. Sobre la libertad, la contingencia y la providencia. In: Escritos em torno a la libertad, el azar y el destino. Tradución de Roberto Rodrígues Aramayo y Concha Roldán Panadero. Madrid: Editorial Tecnos, 1990.

LEIBNIZ, Gottfried Wilhelm. Segunda Carta a Clarke. In: La Polemica Leibniz-Clarke. Edición y traducción de Eloy Rada. Madrid: Taurus Ediciones, 1980 .

LEIBNIZ, Gottfried Wilhelm. Letter to Magnus Wedderkopf. In: LOEMKER, Leroy (eds). Philosophical Papers and Letters. vol 2. Dordrecht: Springer, 1989, p.146-147.

LEIBNIZ, Gottfried Wilhelm. Recherches génélares sur l'analyse des notions et des vérités. 24 thèses métaphysiques et autres textes logiques et métaphysiques. Traduction de Rauzy, J-B; Cattin, E. Paris: PUF, 1998.

LEIBNIZ, Gottfried Wilhelm. Textes inédits.ed. Gaston Grua. Paris: Presses Universitaires de France, 1948.

MARQUES, Edgar. Possibilidade, compossibilidade e incompossibilidade em Leibniz. Kriterion, 109, 2004, pp. 175-187.

MCDONOUGH, Jeffrey. Leibniz's Two Realms Revisited. Noûs, 42(4), 2008, pp.673-696.

OLIVA, Luís César. Vontade divina e contingência na correspondência Leibniz-Arnauld. Síntese - Revista de Filosofia, Belo Horizonte, V. 34, n. 108 (2007), pp. 101-114.

ROLDÁN, Concha. La salida leibniziana del labirinto de la libertad. In: LEIBNIZ, Gottfried Wilhelm. Escritos en torno a la libertad, el azar y el destino. Traducción de Roberto Rodrigues Aramayo y Concha Roldán Panadero. Madrid: Editorial Tecnos, 1990.

RUSSELL, Bertrand. A Critical exposition of Philosophy of Leibniz. Cambridge: 
Cambridge University Press, 1900.

RUTHERFORD. Donald. Leibniz on Spontaneity. In: RUTHERFORD, Donald and COVER, J. A. (eds.). Leibniz: Nature and Freedom. Oxford: Oxford University Press, 2005. pp. 156-180.

SCHNEEWIND, J. B. Locke's Moral Philosophy. In: The Cambridge Companion to Locke. Edited by Vere Chappell. Cambridge: Cambridge University Press, 1994.

TUGENDHAT, Der Begriff der Willensfreiheit. In: Cramer, Konrad. et al. Theorie der Subjektivität. Frankfurt am Main: Suhrkamp, 1987.

WOOD, Allen. Kant's Compatibilism. In: Kant's Critique of Pure Reason: critical essays. Rowman e Littlefield, 1998.

WROBLEWSKI, Igor. Zwei verschiedene Kompatibilismen. Berlin: LIT Verlag, 2014. 